\title{
The mechanical response of UFG and nanostructured microalloyed steels subjected to dynamic loading conditions
}

\author{
Remigiusz Bloniarz ${ }^{1, *}$, Janusz Majta ${ }^{1}$, Carl P. Trujillo², and Ellen K. Cerreta ${ }^{2}$ \\ ${ }^{1}$ AGH University of Science and Technology, Faculty of Metals Engineering and Computer Science, Mickiewicza 30, 30-059 Krakow, \\ Poland \\ ${ }^{2}$ Los Alamos National Laboratory, MST-8, Los Alamos MS755, NM,USA
}

\begin{abstract}
As the number of available, advanced high-strength metallic materials possibilities increases due to advancements in processing (for example advanced thermomechanical processing - ATP or severe plastic deformation - SPD), experimental comparisons alone are not sufficient for determination of the most ideal microstructures for specific applications. Our study deals with the dynamic behaviour of high strength steels and in particular with ultrafine-grained (UFG) microalloyed ferrite and austenite. The forming processes of modern UFG materials require rheological models describing the materials behaviour at large strains and strain rates up to over $1000 \mathrm{~s}^{-1}$. In our case, the mechanical response of UFG steels (produced using MaxStrain system) was investigated with split Hopkinson pressure bar (SHPB) tests, performed at room temperature. The dynamic work-hardening behaviour as a function of solute atoms and fine-scale, secondphase particles in the nano-structures of microalloyed ferrite and austenite has been compared to the mechanical response of these materials under quasi-static loading conditions.
\end{abstract}

\section{Introduction}

The dynamic behaviour of materials has become an important component to the widespread use of many structural materials. The specific properties investigated in the present study could result from the tailored combination of grain refinement and different microstructure components that link back to processing conditions. However, there is still a clear lack of a systematic investigation concerning the effect of grain refinement on mechanical properties measured under high strain rates. The dynamic behaviour of the ultrafinegrained (UFG) microalloyed steels seems to be especially important for many reasons - for example, due to their use in the automotive and energy (pipeline) industries, as high strength structural components. These materials, specifically, show promise, as it has been shown in [1-2]. The smaller grain size bcc metals are much stronger at low rates than their larger grain counterparts, but as deformation and strengthening mechanisms are expected to change at high strain rates [3], the properties of these materials must be examined in the regimes where catastrophic failure can be critical to performance and safety. True understanding and prediction of the performance of these UFG microalloyed steels, will require an understanding of the linkage between dynamic strength and the microalloyed microstructural parameters and mechanical properties, also taking into account the crystal lattice. Material model development - in general, and ultrafine-grained in particular, is largely dependent on continuum scale phenomena and ignores the rich multiscale physical and chemical phenomena that are responsible for the macroscale plastic deformation response of a polycrystalline metal. The substantial complexity of these phenomena, which occur through the evolution of microstructure and texture in response to dynamic loading, presents formidable challenges to theoretical model development of plastic deformation.

In the present research, a laboratory MaxStrain simulator was utilized to apply the SPD to two grades of microalloyed steels i.e. microalloyed ferrite (M_F) and microalloyed austenite (M_A). The objective of this work was to study the effects of microstructure refinement taking place during severe plastic deformation of both steels and following annealing. Additionally, this work investigates the impact of processing conditions on the mechanical response under dynamic loading conditions.

\section{Experimental}

The basic chemical compositions of the investigated steels are summarized in Table 1. The initial materials were supplied in hot rolled conditions. Ultrafine-grained structures were produced using MaxStrain system that is a severe plastic deformation method used to process materials. The principles of this system are described in detail within the literature [4]. 
Table 1. The basic chemical compositions of investigated

\begin{tabular}{|c|c|c|c|c|c|c|c|}
\hline Steel & C & Mn & Si & Ti & Nb & Ni & N \\
\hline M_A & 0.05 & 1.64 & 0.30 & 0.07 & 0.037 & 30.8 & 0.004 \\
\hline M_F & 0.07 & 1.36 & 0.27 & 0.03 & 0.067 & - & 0.009 \\
\hline
\end{tabular}

Distinct from most severe plastic deformation methods, the MaxStrain technology uses deformation in two axes while fully restraining the third axis. More details concerning the methodology employed in the present study can be found in previous works [5-6].

A total strain of 10 and 20 at room temperature was applied during the MaxStrain processing for both of the investigated materials with subsequent annealing at $500{ }^{\circ} \mathrm{C}$ (Table 2). Mechanical properties were measured in quasi-static tension (QST) and compression Split Hopkinson Pressure Bar (SHPB) tests using flat and cylindrical specimens that were cut from the severely deformed materials. The Split Hopkinson Pressure Bar (SHPB) specimens with accumulated strain 10 and 20 were extracted from middle part of MaxStrain specimen (as shown in Fig. 1) which was previously examined for discontinuity and failure presence in the places of sample extraction. Specimens with 0 strain were fabricated from non-deformed "dog bone" part of MaxStrain sample. The cylindrical specimens, 2,5 $\mathrm{mm}$ in diameter and 2,5 $\mathrm{mm}$ high, were dynamically compressed between maraging 350 steel incident and transmitted bars of $9,46 \mathrm{~mm}$ in diameter. Striker $152,4 \mathrm{~mm}$ in length was launched with breech pressure $24,13 \mathrm{kPa}(3,5 \mathrm{psi})$. Two strain rates: $3750 \mathrm{~s}^{-1}$ and $6000 \mathrm{~s}^{-1}$ were applied during SHPB tests. QST test specimens were manufactured from central part in longitudinal axis of specimen, parallel to the previous rolling direction. Tension tests were performed with strain rate of $0.001 \mathrm{~s}^{-1}$.

The microstructural characterization was carried out by transmission electron microscopy (TEM) and scanning electron microscopy (SEM) in electon backscatter

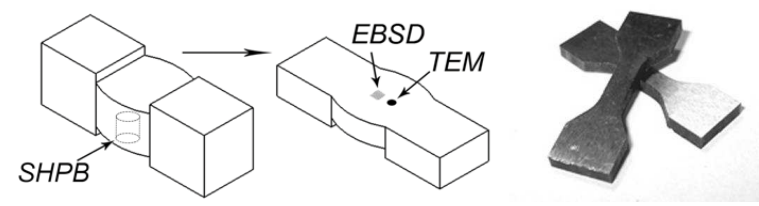

Fig. 1. Sampling places for TEM, SEM (EBSD) and SHPB.

Table 2. MaxStrain processing for investigated materials. $T_{D}-$ deformation temperature, $\mathrm{T}_{\mathrm{A}}$ - post-processing annealing temperature, $\varepsilon$ - total accumulated strain.

\begin{tabular}{|c|c|c|c|c|}
\hline Route & $\mathrm{T}_{\mathrm{D}}{ }^{\circ} \mathrm{C}$ & $\varepsilon$ & Strain rate, $\mathrm{s}^{-1}$ & $\mathrm{~T}_{\mathrm{A}}{ }^{\circ} \mathrm{C}$ \\
\hline M_F_10 & 20 & 10 & 1 & 500 \\
\hline M_F_20 & 20 & 20 & 1 & 500 \\
\hline M_A_10 & 20 & 10 & 1 & 500 \\
\hline M_A_20 & 20 & 20 & 1 & 500 \\
\hline
\end{tabular}

diffraction (EBSD) mode. The mean grain size of the materials were $600 \mathrm{~nm}, 800 \mathrm{~nm}$, in case of total strain of 10 and $400 \mathrm{~nm}, 600 \mathrm{~nm}$ in case of total strain 20 for M_A and M_F, respectively. Sampling places for the mechanical tests, TEM and EBSD are presented in Fig. 1.

\section{Results and discussion}

In ultrafine-grained steels produced by SPD techniques, the formation of an ultrafine microstructure can be attributed to very large accumulated strain and deformation temperature as well as to the heat treatment that was applied to the final products. In the case of microalloying steels, fine precipitates as well as alloying elements in solution play a very important role.

It has been shown [7-9] that the nanoparticle precipitation leads to increased dislocation activity necessary for substructure formation. This was explained in terms of the accumulation of geometrically necessary dislocations. Hence, in the case of microalloyed steels, when the accumulated deformation energy is high enough, the microalloying elements can be beneficial for the ultrafine-grained microstructure development. However, when such UFG materials are subjected to the dynamic loading conditions, a series of questions still remain in relation to the roles of particular strengthening mechanisms. Therefore, presented in this study, experimental results can be successfully used for the further development of a rheological model of the mechanical response of the microalloyed steels subjected to the dynamic loading conditions, where severe grain refinement, dislocation substructure, precipitation and solid solution strengthening are significant.

Results of the SHPB test for both of the investigated steels are presented in Fig. 2. It can be observed that the strong grain refinement causes significant increase in strength. The combined use of SEM, EBSD and plastometric tests enabled the precise study of the mechanical behaviour of the UFG microstructures of the investigated materials as a function of strain rate and the applied SPD schedules. Figs. 2 and 3 show that with rising strain rate, strength increases, and as was expected, this is more pronounced in the case of M_F. The changes of the rate of work hardening of dynamically tested specimens, according to the QST, of M_F and M_A are also significantly different.

As it was shown in [10], the smaller grain size bcc metals are much stronger at low strain rates, but are characterized by less relative strengthening at high strain rates. The total elongation decreases with decreasing grain size and in contrast, has a tendency to increase with increasing the strain rate [11-12].

In the present study, the application of a wide range of strain rates makes it possible to evaluate the strain rate sensitivity of studied materials and its influence on microstructure evolution. Based on the results of the present investigations it can be stated that the change in loading conditions from quasi-static to dynamic rates causes significant discrepancies in dislocation structures evolution and strain rate sensitivity of the final material 
(Fig. 2). Significant differences between microstructures of materials deformed under quasi-static tension (QST) and dynamic compression (SHPB) tests are observed in both of the investigated steels (Fig. 3).

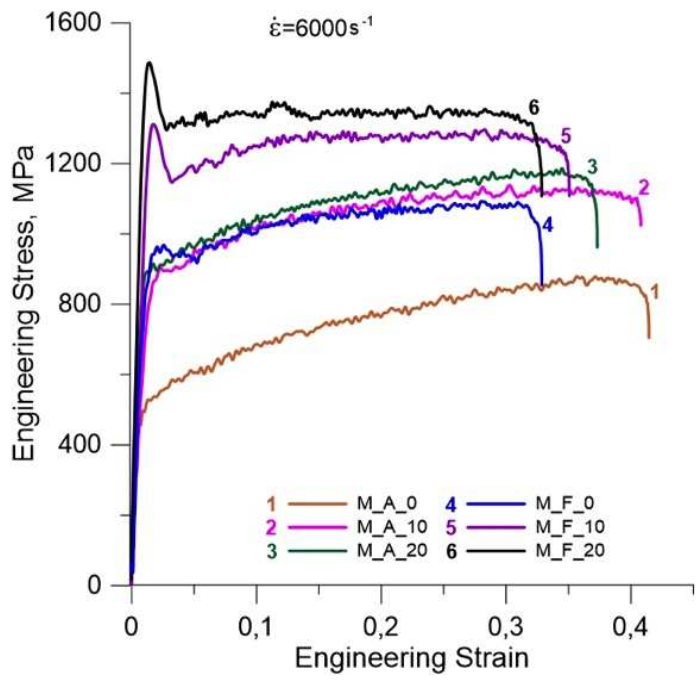

Fig. 2. Comparison of measured during the SHPB tests stress/strain curves of UFG M_F and M_A. The mechanical response of the initial materials i.e. coarse-grained (M_A_0, M_F_0) are also presented.

In order to simulate the real mechanical response of UFG materials there is a need to use an adequate flow stress model that is able to reflect the specific phenomena occurring in such structures. In the case of microalloyed steels the dislocations responsible for creating the cells and subgrains and ultimately the ultrafine-grained microstructures that result from annealing interact with other microstructural features, such as precipitates, impurity atoms and grain boundaries. However, in the case of microalloyed steels, additionally subjected to dynamic loading conditions no clear methodology exists for transfering this knowledge into a proper macroscopic model. The results of complex study of the effect of deformation history, high strain rate and dislocation structure on the mechanical properties of the microalloyed steels [13-15] were incorporated into rheological model, using as a base the Khan-Huang-Liang (KHL) flow stress model [16]. This model has been recently modified to take into consideration contribution in strength from LABs and HABs separately $[14,17]$. In this way, the effects of severe plastic deformation i.e. recrystallization in situ in the creation process of the UFG material has been taken into account. The final form of the model is presented below:

$$
\begin{gathered}
\sigma=\left(a+M \alpha G b \sqrt{1.5 b S_{V} \theta_{L A B}(1-f)}+k \sqrt{\frac{S_{V}}{2} f}\right) . \\
{\left[1+B^{*}\left(1-\frac{\ln \dot{\varepsilon}}{\ln D_{0}^{p}}\right)^{n_{1}}\left(\varepsilon^{p}\right)^{n_{0}}\right]\left(\frac{\dot{\varepsilon}}{\dot{\varepsilon}^{*}}\right)^{C}\left(\frac{T_{m}-T}{T_{m}-T_{r}}\right)^{m}}
\end{gathered}
$$

where: $\sigma$ - flow stress; $a$ - friction stress; $M$ - Taylor factor; $\alpha=0.24 ; G$ - shear modulus; $b$ - Burgers vector; $S v$ - the area of boundary per unit volume $(S v=2 / \mathrm{DB})$ where
$\mathrm{DB}$ is the distance between HABs measured along random lines; $f$-the density of $\mathrm{HABs}, \theta_{\mathrm{LAB}^{-}}$the average misorientation angle of LABs; $\varepsilon_{\mathrm{p}}$ - plastic strain; $D_{0}^{p}=106 \mathrm{~s}^{-1} ; \varepsilon^{*}$ - reference strain rate; $\varepsilon^{2}$ the current strain rate; $T, T_{m}, T_{r}, k, B^{*}, n_{0}, n_{l}, C, m-$ constants. At this stage of the study, the temperature effect was not considered.

a)

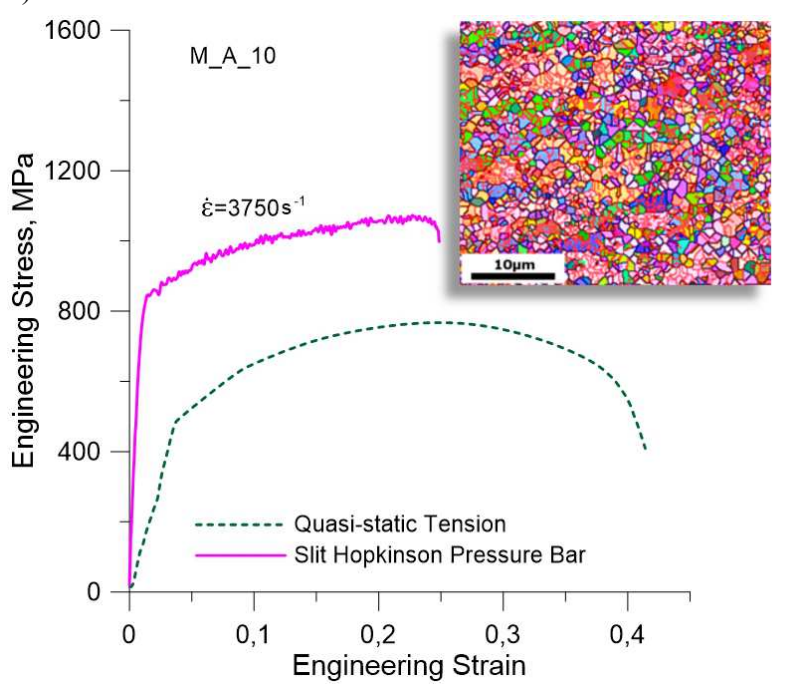

b)

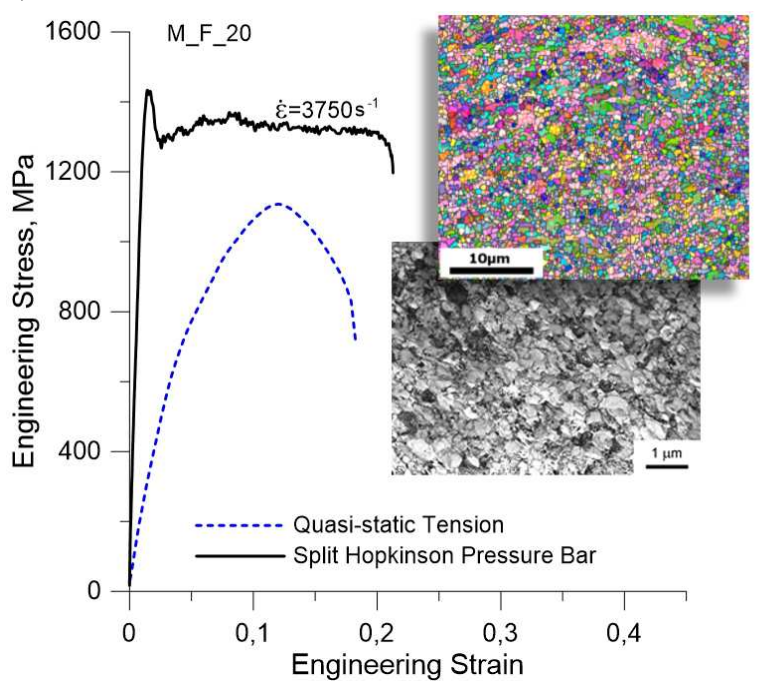

Fig. 3. Comparison of measured during the SHPB and QST tests stress/strain curves of UFG M_A_10 - a) and M_F_20 b) specimens.

The next step of the development process of the rheological model for the deformation of the UFG microstructure (Eq. 1) is the proper representation of the characteristic phenomena under dynamic loading conditions. Presented in this study, results of high strain rate investigations directly support the solution of this problem but further studies are still needed. In Fig. 4 values of the rate of work hardening $v s$. true strain calculated using the existing model were plotted and compared with experimental data. Basing on a true stress-true strain curve and using criteria of plastic instability, there is an opportunity to determine, in an unequivocal way, the field of the uniform elongation by 
Considère's criterion. Good convergence of the model can be observed.

a)

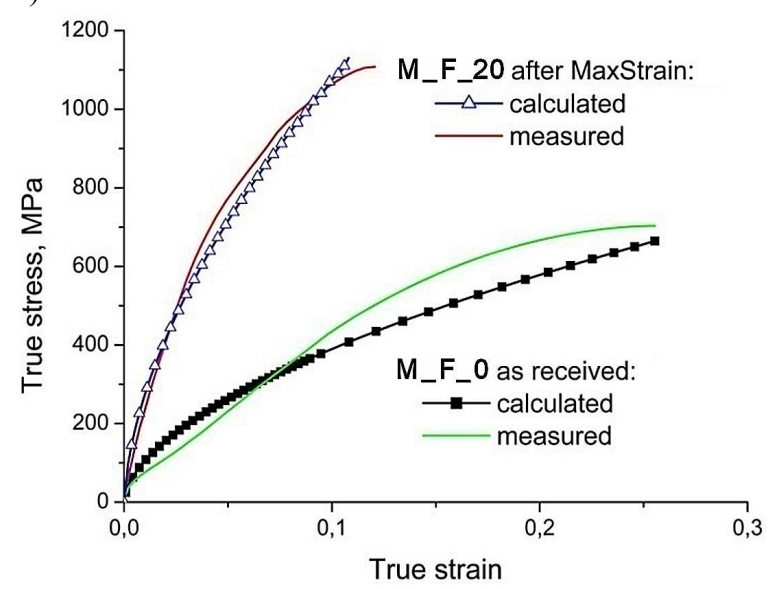

b)

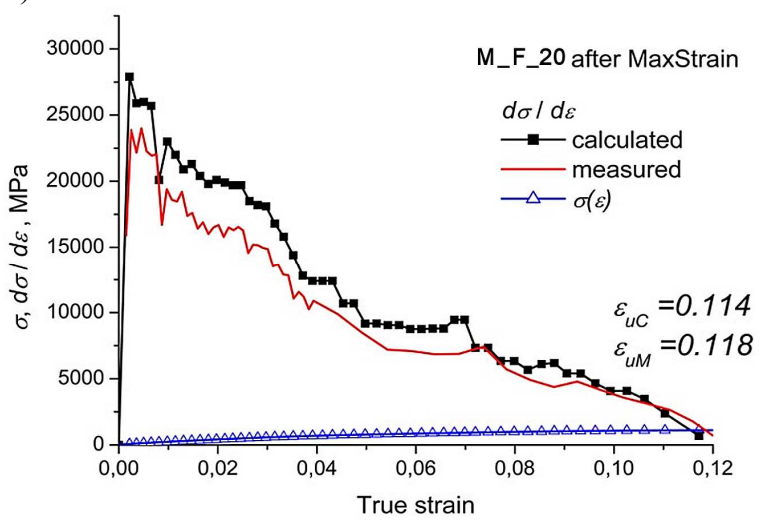

Fig. 4. Example of comparison of calculated and measured stress/strain curves of QST test - a) and uniform elongations (using Considère's criterion) -b) of UFG M_F_20; Calculated uniform elongation $=0.114$, measured $=0.118[5]$.

Figure 4 summarizes calculation results using the modified KHL model. It can be seen, that predicted mechanical behaviour using the proposed model converges with the measured flow stress over the wide range of strains. It should be noticed that in the present stage of study, the model properly reflects most of the important phenomena, which control the work hardening process of UFG microalloyed ferrite. In the next steps further development using results of this study will be made and it is expected that the effects of high strain rates as well as typical work hardening, precipitation and solid solution phenomena in the case of microalloyed austenite (fcc lattice structure) will be properly employed.

\section{Conclusions}

The mechanical responses of ultra-fine grained microalloyed steels (M_F and M_A) produced in MaxStrain multi-compression tests with total strain of 10 and 20 were studied in dynamic (SHPB) and quasi-static (QST) loading conditions. It has been shown that the crystal lattice and chemical composition strongly influences the degree of grain refinement i.e. the fcc lattice and higher content of alloying elements leads to finer grains. These differences result first, from different work hardening mechanisms that operate in these steels. The microstructure evolution during the SPD processing and strengthening mechanisms resulting from microalloying elements (acting both as disperse precipitates and in solid solution) affect the mechanical response of the investigated steels under dynamic loading conditions. It was proved again that unacceptable simplification is to transfer the mechanical response of the investigated microalloyed steels from quasi-static to dynamic loading conditions.

This project is supported by the National Science Center, Poland Grant No 2015/17/B/ST8/00051.

\section{References}

1. A.K. Zurek, K. Muszka, J. Majta, M. Wielgus, 9th Int. DYMAT Conf., (EDP Sciences, Brussels, 2009)

2. K. Muszka, P.D. Hodgson, J. Majta, Mater. Sci. Eng. A, 500, 25-33 (2009)

3. Z.Q. Wang, I.J. Beyerlein, R. LeSar, Int. J. Plasticity, 25, 26-48 (2009)

4. W.C. Chen, D.E. Ferguson, H.S. Ferguson, 42nd MWSP Conference, ISS, 38, 523-532 (2000)

5. J. Majta, K. Muszka, Mater. Sci. Eng. A, 464, 186191 (2007)

6. D.S. Svyetlichnyy, K. Muszka, J. Majta, Comput. Mat. Sci., 102, 159-166 (2015)

7. R. Song, D. Ponge, D. Raabe, J.G. Speer, D.K. Matlock: Mater. Sci. Eng. A, 441, 1 (2006)

8. F. Haessner, Recrystallization of Metallic Materials, (Verlag, Stuttgart, 1978)

9. R. Song, D. Ponge, D. Raabe: Scripta Mater., 52, 1075-1080 (2005)

10. D. Jia, K.T. Ramesh, E. Ma, Acta Mater., 51, 34953509 (2003)

11. N. Takata, Y. Okitsu, N. Tsuji, J. Mater. Sci., 43, 7385-7390 (2008)

12. Y. Cao, Y.B. Wang, X.H. An, X.Z. Liao, M. Kawasaki, S.P. Ringer, T.G. Langdon, Y.T. Zhu, Acta Mater., 63, 16-29 (2014)

13. J. Majta, M. Stefańska-Kądziela, K. Muszka, A. Bator, Proceedings of the 8th International Conference on Technology of Plasticity, 432 (2005)

14. R. Błoniarz, J. Majta, C. Trujillo, E. Cerreta, K. Muszka, Int. J. Impact Eng., 114, 53-62 (2018)

15. J. Majta, K. Muszka, Microstructure Evolution in Metal Forming Processes (Woodhead Publishing in Materials, Philadelphia, 2012)

16. A.S. Khan, Y.S. Suh, X. Chen, L. Takacs, H. Zhang, Int. J. Plast., 22, 195-209 (2006)

17. K. Muszka, J. Majta, P.D. Hodgson, ISIJ Int., 47, 1221-1227 (2007) 